\title{
Explosives magazines in deep and large mines — an overlooked safety issue
}

\author{
A.A. Arzi Israel \\ A.W. Ovalle $A M E C$, Chile
}

\begin{abstract}
As mines become deeper and larger, more explosives are stored underground while the interconnected underground infrastructure and services also expand, thus worsening the catastrophic consequences of a possible accidental explosion of the magazine, in conflict with rising demands for improving overall mining safety. The low probability of such an accident cannot be reduced to zero, but it is possible and justifiable to radically mitigate the consequences, should a magazine explosion occur.
\end{abstract}

\section{Introduction}

Higher consumption rates of explosives in deeper and larger mines increase the tendency to store larger amounts of explosives underground. The capacity of common underground explosives magazines has grown over the years from a fraction of a tonne to tens of tonnes. In parallel, more elaborate infrastructure and services are placed underground, involving many employees and ever larger investments. These parallel trends are worsening consequences of a possible accidental explosion in an underground magazine, while public demands for overall improvement in mining safety are rising. This situation calls for a re-examination of underground magazine safety issues.

Mines vary and this paper neither addresses the full spectrum nor elaborates on any particular mine or technical solution. Rather, showing relevant orders of magnitude, it explains with some simplification the basics of the unusual physics, shows that the magazine explosion risk is of catastrophic consequences with a low probability of occurrence which cannot be reduced to zero, suggests various means of mitigation should an explosion occur and points out the inconsistency of overlooking this worsening safety issue with ongoing demands for improvement of overall safety standards.

\section{$2 \quad$ Airblast in tunnels}

An explosion in air within a system of deep underground tunnels generates effects which are very different from those of a surface explosion in air. In the latter case, the airblast pressures and subsequent gas flows propagate in three dimensions into a volume which increases rapidly, roughly as the third power of the distance from the source. Therefore they dissipate over relatively short distances. In contrast, in an underground explosion, effects are channelled linearly along tunnels, resembling gun barrels, within a volume which increases slowly as the first power of the cumulative distance along the tunnels. Therefore the dissipation is much slower underground.

Even though airblast pressures in the tunnels within tens of metres from a 50 tonne magazine explosion would exceed $10 \mathrm{MPa}$, the tunnels would not be blown open to the surface because the heavy overburden of a deep mine would not be breached. Rockfalls could occur within and near the magazine as the walls rebound following the airblast pressure pulse. However, the rockfall process would be much slower than the airblast propagation and therefore could not significantly interfere with this propagation. Also, rockfalls would most likely be ineffective in blocking subsequent gas flow. Hence, the airblast and gas flow are hereby discussed assuming no significant change in the pre-existing mine tunnels geometry.

An airblast shock wave propagates outward from the explosion site at an initial supersonic velocity, interacting in a complex process with the tunnel walls and with various intersections and obstructions. At the shock-wave front the air pressure rises abruptly from ambient pressure to a peak incident overpressure which later subsides (henceforth in this paper, the word 'pressure' actually means 'overpressure', unless 
specifically stated otherwise). Because of the tunnel confinement, the pressure subsidence with time at any given point, as well as the subsidence with distance along the tunnels, is very slow as compared to surface explosions, i.e. the overall pressure pulse is much longer in the tunnels in addition to being much stronger for the same distance from the source.

The compression and subsequent rarefaction of the air, related to the buildup and relaxation of the incident pressure behind the shock front, involve violent local winds with associated dynamic pressures. Wherever the airblast front encounters a rigid surface which is not parallel to the direction of propagation (e.g. tunnel wall bend, equipment and people in the tunnel) an amplified reflected pressure is generated on that surface. This reflected pressure can be several times higher than the incident pressure. Thus, with some simplification we may say that there is a distinction between the incident 'side-on' pressure which is exerted on surfaces parallel to the propagation such as smooth tunnel walls, reflected pressures which are amplifications at nonparallel surfaces and dynamic pressures caused by the winds behind the shock front. For example, in addition to the incident side-on pressure a person is affected by a reflected pressure due to reflection on the side of his body facing the blast front and, if he stands against a wall, also due to reflection on the wall. He is also dragged by the winds.

Generally, as the airblast engulfs an increasingly larger air volume along the tunnels, associated pressures decrease but their duration increases further.

Due to reflected pressures and winds, people may be thrown off their feet and various objects can be transformed into flying debris, i.e. missiles, typically travelling at subsonic velocities behind the airblast shock wave. Also behind the airblast which races ahead through the mine air, the gas bubble produced by the explosion chemical reactions expands, displacing air and also mixing with it. Through this rapid, essentially adiabatic expansion the gases cool down and their pressure decreases as they occupy an increasingly larger volume, eventually reaching the ambient mine temperature and pressure (zero overpressure).

\section{Representative analysis}

For an exploratory assessment and concrete demonstration of the potential effects of an underground magazine explosion we have considered a 'model mine' as shown in Figure 1, including $50 \mathrm{t}$ of explosives in a single magazine. Although it is somewhat schematic, the relevant parameters of this model are quite similar to those of an existing major caving mine as well as to some designs of future caving mines.

The propagation of airblast and associated effects throughout a maze of interconnected tunnels, shafts etc. is difficult to analyse from basic physics and chemistry principles using a three-dimensional nonlinear dynamic numerical simulation. The distribution of peak incident pressure throughout the mine, resulting from an explosion in one of the tunnels, is a function of the effects at the source, the attenuation along tunnels as a function of their lengths, cross-section areas and wall roughness, the pressure changes due to cross-section changes and tunnel intersections involving various configurations, as well as other factors.

Various limited experimental studies have been reported, suggesting empirical formulas, e.g. for blast pressure attenuation with distance along a single tunnel and for local pressure drops at junctions of various configurations (Taylor, 1968; Britt, 1983; Binggeli, 1983; Smith et al., 1992; Mainiero and Weiss, 1995; Smith and Sapko, 2005; Forsén, 2008; Silvestrini et al., 2009, and various military reports). These data are incomplete and present numerous discrepancies. We have utilised a computational scheme based on judicious application of this material to estimate the distribution of peak side-on airblast pressures generated within the model mine of Figure 1 as a result of a hypothetical explosion of $50 \mathrm{t}$ of explosives in the magazine. Special attention was given to the effects in the service area of the mine, which typically includes offices, shops, dining room, bathrooms, miscellaneous storage and utilities, fuel depots, transportation centres, concrete plant etc. involving a large concentration of people. 


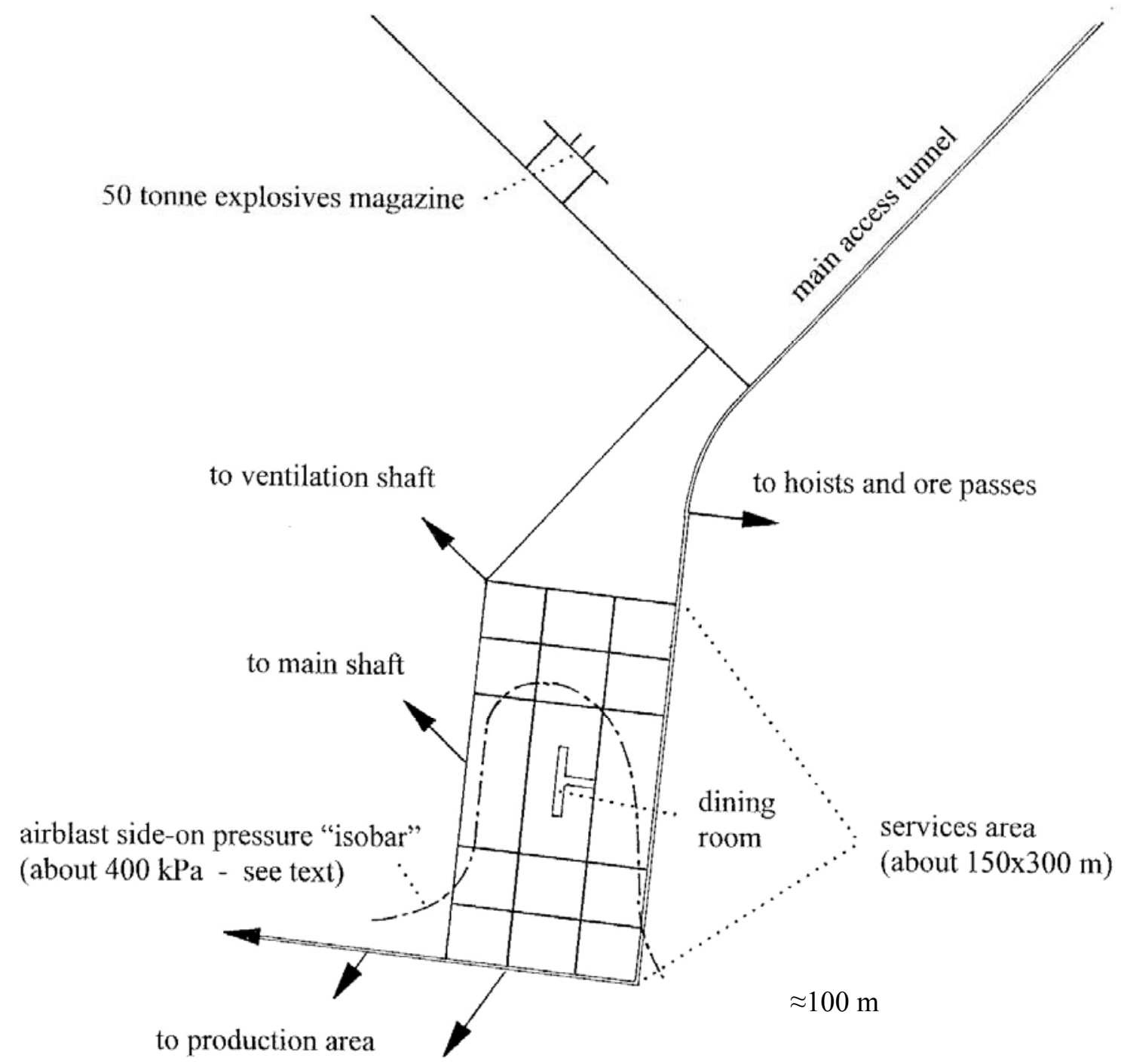

\section{Figure 1 Semi-schematic model mine for discussion of potential magazine explosion effects}

We do not make a distinction between different explosives because, per unit weight, the relevant airblast pressures due to all presently common mining explosives are similar to within $\pm 20 \%$ or so (Baker, 1973 ; DoD, 2008b; Sadwin, 1970) - a range which is insignificant in comparison to the other relevant variations. In particular, it should be noted that it is erroneous to consider ANFO as being significantly less destructive than dynamite or TNT in case of an accidental explosion (e.g. an 'equivalence' of $4 \mathrm{~kg}$ ANFO to $1 \mathrm{~kg}$ dynamite or $0.9 \mathrm{~kg}$ TNT is stated in some Chilean and Peruvian regulations).

\section{$4 \quad$ Pressure magnitudes}

Our analysis of the $50 \mathrm{t}$ explosion in the model mine shows that the airblast front reaches the edges of the services area, through the shortest routes from the magazine (about $400 \mathrm{~m}$ length in Figure 1) with peak sideon pressures in the order of $2 \mathrm{MPa}$. This is a pressure level at which common reinforced concrete walls are breached and it is much higher than the 100\% lethality level (in comparison, for an aboveground free-air explosion this is the pressure level less than $30 \mathrm{~m}$ from a $50 \mathrm{t}$ blast!). From the perimeter of the service area inward the pressures drop at a relatively rapid pace due to dissipation within the large volume of air and complex geometry in this area. A representative $400 \mathrm{kPa}$ side-on pressure 'isobar' is drawn through this area in Figure 1. Within the dining room, situated about the centre of the service area, the side-on pressure reaches a local minimum around $40 \mathrm{kPa}$ according to our estimates. The edge of the production area is 
reached by the airblast through the shortest routes from the magazine with peak side-on pressures around $300 \mathrm{kPa}$ and the pressures dissipate rapidly within the large air volume of the production area.

Because of the ambiguity in the underlying empirical data base and since the assessment involves miscellaneous details which could vary from mine to mine, all of the above pressure estimates merely indicate orders of magnitude. A more elaborate analysis, possibly including a test of a physical small-scale model or small calibration blasts in an existing mine, may be justifiable for a specific project to provide more exact answers to specific design-related questions.

It may be noted that the above airblast pressures are, in order of magnitude, similar to those generated by major methane and coal-dust explosions in coal mines. The airblast pressures generated by caving and large rockfalls are typically much lower, although occasionally even such events cause significant injuries and damage.

The pressures discussed above are only side-on pressures. Associated reflected pressures can be much higher, e.g. up to about $100 \mathrm{kPa}$ and $1,600 \mathrm{kPa}$ for peak side-on pressures of $40 \mathrm{kPA}$ and $400 \mathrm{kPa}$, respectively.

The distinction and importance of reflected pressures is perhaps exemplified in the following case. On 2 March 1910, at the Mexican gold mine in Alaska, an underground powder magazine exploded due to an undetermined cause, resulting in the death of 37 miners (NIOSH, 2010). According to a report in The New York Times of 4 March 1910, the magazine contained only $125 \mathrm{~kg}$ of 'powder'. The report also observed that '... two horses in the mine were standing side by side. One was killed, but the other, when found, was munching oats undisturbed'. A plausible explanation for the latter observation is that the body direction of the horses was perpendicular to the tunnel axis. The upstream horse could have been killed by the reflected pressures on its upstream body side and/or by flying debris, sheltering the downstream horse from both effects. The latter horse was affected by a side-on pressure which happened to be below the injury level.

\section{Pressure consequences}

In studying the capacity of injuring and damaging of an airblast, it must be remembered that in the tunnels we are dealing with pressure pulses of long duration, typically in the order of tens to hundreds of milliseconds, approaching the length of pulses generated by nuclear explosions, in contrast to the typical shorter pulses of conventional surface explosions. The longer duration results in a higher overall impulse for the same peak pressure level. A survey of pertinent literature (e.g. Glasstone and Dolan, 1977; Zipf et al., 2007; DoD, 2008a) shows the consequences corresponding to such long-duration pulses for the following effective peak pressure levels (which are relevant combinations of side-on and dynamic or reflected pressures). These representative levels roughly cover the range of effective peak pressures expected within the service area of the Figure 1 model mine due to the 50 tonne explosion:

- $40 \mathrm{kPa}$ - about a $10 \%$ probability of eardrum rupture, vehicle damage, light wall destruction including brick and cinder block. If $40 \mathrm{kPa}$ is the side-on pressure then reflected pressures may reach up to $100 \mathrm{kPa}$ and winds up to $280 \mathrm{~km} / \mathrm{hr}$ (higher than the velocity inside hurricanes).

- $100 \mathrm{kPa}$ - about a $50 \%$ probability of eardrum rupture, beginning of lung haemorrhage. If $100 \mathrm{kPa}$ is the side-on pressure then reflected pressures may reach up to $270 \mathrm{kPa}$ and winds up to $660 \mathrm{~km} / \mathrm{hr}$.

- $400 \mathrm{kPa}$ - about a $50 \%$ lethality due to lung rupture, unreinforced concrete walls breach. If $400 \mathrm{kPa}$ is the side-on pressure then reflected pressures may reach up to $1,600 \mathrm{kPa}$.

- Over $700 \mathrm{kPa}-100 \%$ lethality.

To put such values in perspective it should be noted that the U.S. Department of Defense (DoD) minimum Inhabited Building Distance against accidental explosions is based on a limit of only about $6 \mathrm{kPa}$ for side-on pressure (i.e. up to $12 \mathrm{kPa}$ reflected pressure - just under the eardrum rupture threshold) from long-duration pulses (DoD, 2008a). According to these U.S. and similar NATO regulations, if applied to the model mine of Figure 1 with interpretation of the services area as an 'inhabited building', the quantity of explosives stored in the magazine would be limited to a fraction of a tonne. Various regulations governing civilian and military intentional explosions require for people an even much lower airblast limit of about $0.2 \mathrm{kPa}$, which is roughly the threshold of ear pain and injury. 
We may thus conclude regarding pressure consequences, as exemplified by the representative 50 tonne explosion in the model mine of Figure 1. If a magazine explosion generated side-on airblast pressures in the order of tens to hundreds of $\mathrm{kPa}$ in and around the service area of a large underground mine, as well as higher pressures in tunnels closer to the explosion, then the injuries and damage due to direct pressure effects could clearly be of a catastrophic scale. It should also be noted that such airblast pressures would throw cages and skip buckets in their shafts as well as damage and immobilise vehicles in access tunnels, thus hindering rescue efforts.

\section{Impact consequences}

Airblast winds and reflected pressures in the aforementioned orders of magnitude, as well as subsequent lesser but more protracted winds associated with the gas expansion, can throw people off their feet and hurl them onto ground or walls, rip fixtures off walls, break partitions and transform such materials and various equipment pieces, stones etc. into flying debris, i.e. missiles, which can cause injury and death upon impact. At the conditions estimated for the 50 tonne explosion in the model mine, the overall contribution of such impact effects to injury and damage can be of an order similar to that of the direct pressure effects, or worse. Again, all of these effects could greatly exceed the typical pressure and impact effects associated with airblasts due to caving or large rockfalls, with which miners are relatively acquainted.

\section{Gas consequences}

An explosion of typical mining explosives transforms them into gases, essentially devoid of oxygen. This dust-laden gas is asphyxiating and also contains toxic ingredients. After the gas rapidly expands and cools down to the ambient mine pressure (zero overpressure) and temperature, the gas due to each kilogram of any such explosive occupies about one cubic metre. A 50 tonne explosion would thus generate about 50,000 cubic metres of gas, which is, for example, the volume of 20 square metre tunnels with a cumulative length of $2.5 \mathrm{~km}$. This bubble of gas would expand through the tunnels in a high-velocity turbulent flow, displacing the air and also mixing with it. This mixture, still asphyxiating and toxic, would therefore eventually occupy a much larger overall volume and it would likely engulf most of the portion of the model mine shown in Figure 1.

Even an intact ventilation system would be unable to cope immediately with such a deluge of gases, let alone a with a system failure due to airblast damage to partitions, ducts and fans. The explosion gases would not spread in the relatively slow convective process of smoke and gases emitted by a fire, which would typically leave some fresh air pockets near the floor due to stratification. Rather, the high-pressure driven explosion gases would engulf the affected mine section within seconds, in a vigorously mixing turbulent flow, leaving little if any pockets of fresh air. When, for example, two parts by volume of no-oxygen gas are mixed (even without any further oxidation reactions) with one part normal air, the mixture has a diluted oxygen concentration of about $7 \mathrm{vol} \%$ and in such an atmosphere fainting occurs after about three minutes and death in about eight minutes (NASA, 1997; DNV, 2001). The situation is made worse by toxic ingredients. To escape in the appropriate direction, activate an adequate self-rescue breathing apparatus or reach a suitable refuge chamber, a victim would have to somehow act very quickly and effectively in spite of having just suffered airblast and impact injuries. Thus, the combination of airblast pressure effects, impact effects and asphyxiating gases could be far more disastrous than any of these effects alone.

\section{Probability versus consequences}

The above analysis shows that an accidental magazine explosion with parameters in similar orders of magnitude could have catastrophic consequences. Depending mainly on the number and distribution of people in the mine at that moment, tens to hundreds could be seriously injured, including numerous deaths. Severe damage to infrastructure and equipment would be extensive and a lengthy loss of production would ensue.

The risk of a disastrous event is a function of its probability of occurrence and its consequences. The probability of a magazine explosion in a deep underground mine is evidently low but not negligible. Generally, most military ammunition depots and civilian explosives magazines are aboveground. Several accidental explosions of the former have been reported worldwide in recent decades whereas explosions of 
the latter are apparently rare. Since a massive explosion typically obliterates evidence, the causes are rarely understood.

An example of an underground magazine explosion in a modern mine is provided by Knee (2006). In 2005, at a mine in Western Australia, an underground magazine containing 'in excess of six tonnes' of ANFO caught fire. The cause of the ignition was not determined with certainty. The magazine exploded two hours after they had become aware of the fire. The fortunate time delay enabled evacuation of all personnel without any serious injuries, but the report notes that 'The potential for serious consequences is, however, obvious'. Reportedly 'The fire and subsequent explosion caused significant damage to services, ventilation doors and machinery up to a kilometre away'. The explosion also knocked out the underground communications and stopped two surface fans. The 'so-called working party magazine' had been apparently operated with lessthan-exemplary safety precautions and the report notes that over the years such magazines had grown from about $100-200 \mathrm{~kg}$ up to multi-tonne quantities and that 'The regulatory provisions, as they were originally developed, did not envisage catering for the levels of usage occurring today'. Be it as it may, the fact is that such an explosion has occurred recently in a leading mining country noted for its overall mining safety record.

In principle, no regulations and enforcement concerning the conduct of operations within and around explosives magazines can ever guarantee total elimination of an explosion probability. One reason is the ever-present possibility of detonation caused by fire in spite of all precautions. This includes, among various other reasons, the possibility of spontaneous ignition, the possibility the fire may not be immediately detected and the possibility the fire could turn into a detonation within minutes. Another related reason is the human factor. In addition to human lack of judgment or negligence, the risks of sabotage and terrorism also exist. For example, as reported by Gatehouse (2002), in 1992 at the Giant gold mine in Canada, a union miner used $38 \mathrm{~kg}$ of stolen mine explosives to kill nine strike-breaking miners by a trip wired bomb underground. Shocking as it is, it happened - in a leading mining country, in spite of all regulations and extra vigilance of police and guards during the strike. A magazine could be sabotaged in similar circumstances.

It thus appears that an underground magazine explosion is a low-probability high-consequence (lp-hc) event, the probability of which cannot be reduced to absolute zero by any precautions. It is however possible to mitigate the consequences, should an explosion occur in spite of all precautions.

\section{Mitigation of consequences}

Various degrees of reduction of the consequences of an underground magazine explosion, should it occur, can be achieved by one of various means, or by a combination thereof, selected to suite the overall mine configuration, operational requirements and other ad-hoc considerations. The following are examples of such means:

- A mine may be designed considering greater distance between the magazine and areas with high concentrations of people and equipment, including structures such as debris traps, expansion chambers and special pressure-relief shafts or tunnels leading to the surface or into large-volume abandoned workings etc. especially between the magazine and the services area. This approach in itself provides only partial mitigation, it may be more difficult to implement as a retrofit in an existing mine and it is not likely to be cost effective in comparison to other methods.

- The explosives stored underground may be distributed among several small magazines, separated from each other by an adequate combination of distances and closure devices so as to preclude sympathetic detonation. For example, in a given configuration of underground spaces, relative to an explosion of a 50 tonne magazine, an explosion limited to $5 \mathrm{t}$ would reduce the airblast pressures in the relevant range roughly by a factor of 6 and the amount of asphyxiating gases by a factor of 10 , substantially reducing the disastrous consequences. Still, also this approach, in itself provides only partial mitigation, is difficult to retrofit and is not likely to be relatively cost effective.

- The mine may choose to avoid substantial underground storage altogether, making special arrangement for just-in-time supply of explosives from surface storage, perhaps through a dedicated shaft. This could be a radical solution, applicable also for retrofitting an existing mine. 
- The connection between the explosives magazine and the rest of the underground mine may be limited to a tunnel in which a set of two massive blast doors is positioned, one after the other, electronically controlled so that at any moment at least one of the doors shall be closed. To lessen the dynamic design load for these doors, structures such as debris traps, expansion chambers, deflectors and turbulence inducing roughness elements may be positioned between the magazine and the doors. Instead of the two doors, a single blast-activated automatic closure block may be employed, however, it may be less reliable. A single non-automatic blast door can partially reduce the risk, roughly in proportion to the fraction of time during which it is maintained closed.

The two blast doors isolation solution may have the widest applicability, involving a local structure which may also be retrofitted into an existing mine without changing the existing magazine and its mode of operation. It is a radical and reliable solution, technically feasible, possibly the most cost effective and its cost will not be prohibitive within the overall costs associated with a major deep mine.

It may be interesting to note that significant mitigation of explosion airblast pressures may be achieved if stored explosives are closely surrounded by tanks containing a larger quantity of water (e.g. Absil and Bryntse, 2006). Conceivably, such water may also be used for rapid automatic fire fighting. However, the effect has not been tested at the multi-tonne scale and various aspects clearly require further research. The large amount of water vapour added to the explosion gases may extend the asphyxiation zone and the duration of gas flow winds. In fact, significant airblast suppression could be achieved by surrounding the explosives pallets with various other energy-absorbing materials, including sandbags. However, any such means would only give partial mitigation at its best and it is doubtful that it would be operationally acceptable.

\section{Discussion}

Overall, the disastrous consequences of a magazine explosion, as exemplified by the analysis of the 50 tonne explosion in the model mine of Figure 1, in terms of loss of life, injuries, destruction and loss of production, could be of the same order as the consequences of a major methane and coal-dust explosion in a coal mine, considering the high concentrations of people in the services area of a large deep mine. Coal mine explosions evidently have a much higher probability than a magazine explosion, the causative methane and coal dust are inevitable products of coal mining - difficult to control always and everywhere at costs which may be prohibitive at places - and the disastrous consequences are difficult to mitigate should an explosion occur somewhere in a coal mine. Nevertheless, coal mine catastrophes are becoming unacceptable in the modern world. In comparison, magazine explosions have a very low probability but they are essentially man made at a pre-determined location and, as discussed above, disastrous consequences can be prevented at nonprohibitive costs, should even an explosion occur. It thus appears that such catastrophes should also be regarded as unacceptable.

Another comparison may be made to the well established U.S. Department of Defense (DoD, 2008a) regulations concerning accidental explosions. As aforementioned, if these regulations were applied to the model mine of Figure 1 with the service area regarded as an 'inhabited building', then the magazine capacity would be limited to a fraction of a tonne. The DoD regulations were written mainly for military magazines whereas the probability of a mine magazine explosion is apparently lower, but again - the latter probability is not zero and the consequences of even one such explosion could be catastrophic.

Chilean regulations (Ministerio de Defensa Nacional, 1982), which formally apply also to civilian mining magazines, require for an aboveground magazine surrounded by a protective parapet a minimum distance to inhabited buildings of $670 \mathrm{~m}$ for a 50 tonne capacity, in rough agreement with U.S. DoD regulations. No parallel formula is given for an underground magazine, but to achieve a similar attenuation of airblast within a tunnel system the equivalent distance along typical tunnels should be several kilometres between the underground magazine and the services area, if the latter is regarded as an inhabited building. Thus, the situation represented by our model mine analysis is incompatible at least with the logic of such safety regulations, although they do not state any underground safety distances.

Research (e.g. Michel-Kerjan and Slovic, 2010) and current examples of catastrophes in various countries show the difficulties of contending with the risk of low-probability high-consequence (lp-hc) disasters, which are often subject to 'will not happen to me' or 'not in my term of office' attitudes before an 
occurrence, but over-reaction involving the media and politicians after an occurrence. We do not attempt an actuarial calculation of the proper risk-based insurance premium, or justifiable investment in risk elimination measures. However, it appears that an investment in the order of a few million dollars, e.g. for a complete blast doors arrangement, is justifiable as a means to eliminate the possibility of a catastrophe as described above even if a large underground magazine does explode. Such an investment is certainly not prohibitive in the framework of a large deep mine.

\section{Regulatory implications}

In light of the above discussion, it may be argued that protection against consequences, in case such an underground magazine does explode, should be mandatory where appropriate. Cursory sampling shows that regulations governing underground explosives magazines, even in advanced mining countries, are generally deficient in this respect, concentrating on subjects such as security, precautions against ignition, fire fighting etc. but essentially avoiding serious treatment of mitigating the consequences of a massive explosion, should it occur.

A mitigation-related example in a Chilean regulation (Ministerio de Defensa Nacional, 1982) requires excavation of a $3 \mathrm{~m}$ deep expansion chamber in front of a crosscut which serves as an underground explosives magazine, if it contains more than $100 \mathrm{~kg}$ of explosives. This regulation at least implicitly acknowledges the possibility of airblast due to an underground magazine explosion. However, even against a $100 \mathrm{~kg}$ explosion the effect of such a small chamber is questionable. Against a multi-tonne explosion it is meaningless.

A Spanish regulation (Ministerio Industria y Energía, 1986) goes farther and limits an underground magazine capacity to one tonne if it is close to working areas where people are usually present. Also, it requires that in case of an accidental explosion the airblast overpressure must not exceed $40 \mathrm{kPa}$ where the presence of people is permanent and $200 \mathrm{kPa}$ where it is temporary. The regulation also includes some unclear instructions for the calculation of overpressures and for the excavation of expansion chambers etc. This regulation still allows harmful overpressures while imposing a harsh one-tonne limit and we do not know, where and how this limit is actually enforced. Clearly, there are better means to treat this safety issue.

Most magazine regulations were probably written originally when explosives magazines contained no more than a fraction of a tonne, not tens of tonnes of explosives, when overall safety standards were lower and when the scale of investment in a major deep mine of today was unheard of. Unfortunately, safety regulations are typically written and revised in response to accidents, but are otherwise copied from jurisdiction to jurisdiction and from generation to generation. Large-scale deep mining is clearly in a state of rapid expansion and a large underground magazine explosion in a major deep mine is a distinct possibility, with potentially catastrophic consequences. It is obviously preferable to prevent such a catastrophe proactively, before one happens.

\section{References}

Absil, L. and Bryntse, A. (2006) Blast mitigation by water, FOI-Swedish Defence Research Agency Report no. FOI-R-2049-SE.

Baker, W.E. (1973) Explosions in Air, U. of Texas Press, 268 p.

Binggeli, E. (1983) Blast wave propagation in cross-branched tunnels, in Proceedings 8th Int. Symp. on Military Applications of Blast Simulation, Spiez, Switzerland.

Britt, J.R. (1983) Attenuation of short duration airblast in tunnel systems, in Proceedings 8th Int. Symp. on Military Applications of Blast Simulation, Spiez, Switzerland.

DNV (2001) Human Resistance against Thermal Effects, Explosion Effects, Toxic Effects and Obscuration of Vision, DNV Technica, Scandpower A/S, Det Norske Veritas, Norway.

DoD (2008a) U.S. Department of Defense (DoD) Ammunition and Explosives Safety Standards, U.S. Department of Defense Document 6055.09-STD.

DoD (2008b) U.S. Department of Defense (DoD) Structures to Resist the Effects of Accidental Explosions, U.S. Department of Defense Document UFC 3-340-02.

Forsén, R. (2008) Tunnel explosion characteristics, in Proceedings 3rd Int. Symp. on Tunnel Safety and Security, Stockholm, Sweden.

Gatehouse, J. (2002) Giant mine murders: ten years later, The Canadian Encyclopedia, Historica Foundation of Canada. Glasstone, S. and Dolan, P.J. (1977) The Effects of Nuclear Weapons, U.S. Department of Defense, 653 p. 
Knee, M. (2006) Fire and explosion in a working party magazine, Government of Western Australia Mines Safety Bulletin No. 75.

Mainiero, R.J. and Weiss, E.S. (1995) Blast wave propagation in underground mines, in Proceedings 11th Symposium on Explosives and Blasting Research, Nashville TN.

Michel-Kerjan, E. and Slovic, P. (eds) (2010) The Irrational Economist: Making Decisions in a Dangerous World, Public Affairs, 324 p.

Ministerio de Defensa Nacional (1982) Reglamento complementario de la ley no. 17.798, Decreto Supremo no.77, Art. 82-84, Chile.

Ministerio Industria y Energía (1986) Instrucción ITC 10.0-01, Publicación BOE 11-4-1986, núm. 87, Spain.

NASA (1997) Safety Standard for Hydrogen and Hydrogen Systems, NSS 1740.16, U.S. National Aeronautics and Space Administration.

NIOSH (2010) Metal/nonmetal mining disasters, U.S. National Institute for Occupational Safety and Health, viewed 23 January 2010, http://www.cdc.gov/niosh/mining/statistics/dismnm.htm.

Sadwin, L.D. (1970) Ammonium nitrate/fuel oil, a safer airblast source, 12th ASESB Explosives Safety Seminar, Memphis TN.

Silvestrini, M., Genova, B. and Leon Trujillo, F.J. (2009) Energy concentration factor: a simple concept for the prediction of blast propagation in partially confined geometries, Journal of Loss Prevention in the Process Industries, Vol. 22, pp. 449-454.

Smith, P.D., Mays, G.C., Rose, T.A., Teo, K.G. and Roberts, B.J. (1992) Small scale models of complex geometry for blast overpressure assessment, Int. Journal of Impact Engineering, Vol. 12, No. 3, pp. 345-360.

Smith, A.C. and Sapko, M.J. (2005) Detonation wave propagation in underground mine entries, Journal of The Mine Ventilation Society of South Africa, Vol. 58, No. 1.

Taylor, W.J. (1968) Blast wave behaviour in confined regions, Prevention of and Protection against Accidental Explosion of Munitions, Fuels and other Hazardous Mixtures, Annals of the New York Academy of Sciences, Vol. 152, 339 p.

Zipf, R.K., Sapko, M.J. and Brune, J.F. (2007) Explosion pressure design criteria for new seals in U.S. coal mines, Information Circular 9500, U.S. National Institute for Occupational Safety and Health. 
